\title{
Patología en pollos inoculados oralmente con diferentes concentraciones de ooquistes de Toxoplasma gondii
}

\author{
ANA ISELA RUÍZ*, MISAEL CHINCHILLA* y OLGA GUERRERO*
}

\section{PATHOLOGICAL RESPONSES OF DOMESTIC CHICKENS AFTER ORAL INOCULATION WITH DIFFERENT CONCENTRATION OF Toxoplasma gondii OOCYSTS}

Five days old chicken (Gallus domesticus) were infected per os with $10^{1}, 10^{3}$ or $10^{5}$ Toxoplasma gondii oocysts. The infection development was monitored studying symptoms, survival time and antibody presence in these chickens. Severe diarrhea, anorexia and weight loss were present before death that start 5 days after infection. Survival time was lower in those animals infected with a higher oocyst number. Small intestine, liver and lung presented more intense pathology and antibody production started 10 days after infection, increased after 20 days and then declined. The importance of these findings relating to the role of chickens in the transmission of $\boldsymbol{T}$. gondii, is discussed.

Key words: Toxoplasma gondii, chicken, epidemiology, Costa Rica.

\section{INTRODUCCIÓN}

Costa Rica, al igual que en otros países de la América tropical y subtropical, es uno de los países de mayor prevalencia de la toxoplasmosis, llegando en algunas áreas del país a más del $85 \%$ de la población de 18 a 25 años ${ }^{1}$.

Aparte del conocimiento que ya se tiene en Costa Rica de la presencia del Toxoplasma gondii en los hospederos intermediarios naturales como ratones y $\operatorname{ratas}^{2}$, bovinos y porcinos ${ }^{3,4}$, resulta también importante conocer lo que sucede con las infecciones en pollos y gallinas, que han sido encontrados positivos por este parásito en un $54 \%{ }^{5}$ y son de amplio consumo en la población del país. Además se debe tomar en cuenta que estas aves se infectan ingiriendo los ooquistes del parásito que se encuentran en el suelo el cual en Costa Rica presenta un alto índice de contaminación ${ }^{6}$. Sin embargo no se tiene una idea clara de lo que sucede en estos animales después de la infección, por lo que en este estudio se pretende establecer el proceso de seroconversión en los pollitos, además de la patología que se produce en ellos, de acuerdo con la cantidad de ooquistes ingeridos.

\section{MATERIAL Y MÉTODOS}

En el trabajo se emplearon pollitos (Gallus domesticus), de 5 días de nacidos, con un peso promedio de $53 \mathrm{~g}$. Para determinar indirectamente

Centro de Investigación en Enfermedades Tropicales (CIET), Departamento de Parasitología, Facultad de Microbiología, Universidad de Costa Rica.

Dirección para correspondencia: Misael Chinchilla. Departamento de Parasitología, Facultad de Microbiología, Universidad de Costa Rica. San José, Costa Rica, América Central. Teléfono: \# 207-42-77. Fax: 225-23-74 / 22543-84. 
las infecciones de los pollitos por el parásito se utilizaron ratones blancos de la cepa NGP con un peso de 20-25 g. Para la infección se utilizaron ooquistes de $T$. gondii cepa TCR $-2^{7}$ que se obtuvieron por concentración de las heces de un gato previamente infectado y madurados posteriormente en ácido sulfúrico al 2\% (3-4 días). Tales ooquistes fueron lavados con solución salina al $0,85 \%$ contados en una cámara de Neubauer para luego preparar inóculos de $10^{1}, 10^{3}$ y $10^{5}$ por $\mathrm{ml} \mathrm{e}$ inocular oralmente los pollos de acuerdo con el siguiente esquema: grupo 1: animales no inoculados, grupo 2: infectados con $10^{1}$ ooquistes, grupo 3: infectados con $10^{3}$ ooquistes, grupo 4: infectados con $10^{5}$ ooquistes.

Taquizoitos de la cepa RH de características conocidas fueron usados en la preparación del antígeno para los estudios sexológicos ${ }^{8}$.

Los pollitos de cinco días fueron sangrados con lancetas de la vena del ala, recogiéndose la sangre en un capilar para obtener de esa manera los sueros que fueron congelados a $-20^{\circ} \mathrm{C}$ para su uso posterior en los estudios serológicos.

A los pollos que murieron en el transcurso del experimento se les hizo la autopsia y sus órganos se fijaron en formalina al 10\%, para estudiar posteriormente las lesiones causadas por T. gondii. El intestino delgado se fijó en el líquido de Zenker, inyectando en el lumen formalina al $10 \%{ }^{9}$. También se fijaron hígado, pulmón y bazo cuyos cortes histológicos se estudiaron posteriormente.

Los pollitos se sacrificaron a los 30 días revisando microscópicamente por presencia de quistes en el cerebro o inoculando éstos oralmente en ratones para comprobar la infección. Los sueros de los pollitos y de los ratones se analizaron serológicamente por medio de la técnica de inmunofluorescencia indirecta (IFI) del CDC para determinar la presencia de anticuerpos contra $T$. gondii preparando laminillas que fueron guardadas a $-20^{\circ} \mathrm{C}$ después de secarlas al aire.

\section{RESULTADOS}

Los pollos presentaron una diarrea severa, debilidad, anorexia y pérdida de peso y los que recibieron una mayor cantidad de ooquistes, se empezaron a morir después de 5 días siendo la supervivencia inversamente proporcional al inóculo (Figura 1).

Al realizar la autopsia de los pollos que murieron al inicio de la infección con el parásito, algunas vísceras se encontraban edematosas y con focos hemorrágicos; los pollos que sobrevivieron continuaron con diarrea durante 10 a 15 días post inóculo. En general las aves presentaron en los primeros días de la infección, bajo peso, cresta pálida, plumaje ralo y erizado, además tenían hematomas, equimosis y petequias en la piel. Los pollos control (no infectados) crecieron normalmente, eran activos y comían bastante, no tenían diarrea y su plumaje era más sano.

Los órganos más afectados fueron el intestino, el hígado y el pulmón (Figura 2). Todo el intestino delgado presentaba la pared engrosada, amarillenta y con una inflamación muy evidente, observándose puntos hemorrágicos y diversos hematomas, siendo éstos más numerosos en la parte proximal. El pulmón estaba lesionado casi en su totalidad, con gran cantidad de focos hemorrágicos y conglomerados de linfocitos, macrófagos y polimorfonucleares, además presentaba un proceso necrótico de hemorragia y coágulos en los bronquios. Se encontraron taquizoitos de $T$. gondii en mayor cantidad en los pulmones de los animales inoculados con $10^{3}$ y $10^{5}$ ooquistes de parásito.

Una leve esplenomegalia fue observada especialmente en los animales con inóculos de $10^{3}$ y $10^{5}$ ooquistes y presentando el bazo zonas oscuras de necrosis.

En el hígado se encontraron necrosis y centros germinativos bien definidos, fibrosis perivascular con la presencia, en la mayoría de los casos, de taquizoitos de $T$. gondii en grupos o aislados, siendo ese órgano uno de los más afectados por este parásito tanto macro como microscópicamente, en especial en los pollos con inóculos más altos.

Se encontró que los animales control siempre presentaron serología negativa, mientras que los pollos inoculados levantaron un título evidente de anticuerpos después de 10 días de infección, aumentando a los 20 días para luego declinar rápidamente. Como era de esperar, los pollos inoculados con 10 ooquistes presentaron títulos más bajos de anticuerpos que aquellos animales infectados con $10^{3}$ y $10^{5}$ ooquistes.

Al estudiar los cerebros de los pollos por subinoculación en ratones, no se pudo determinar la presencia microscópica del parásito pero si existió seroconversión evidente en los animales 

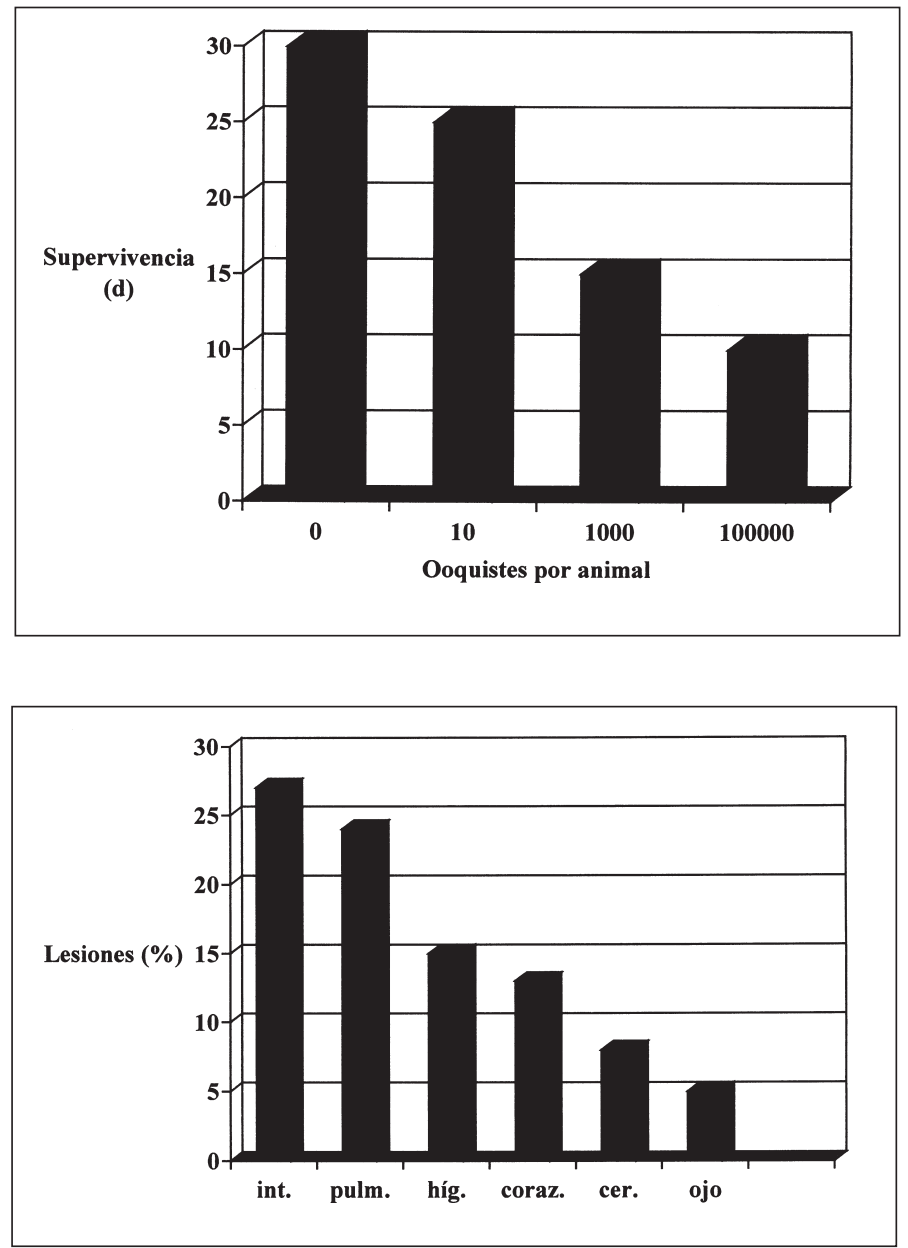

Figura 1. Supervivencia de pollos inoculados con T. gondii.

Figura 2. Lesiones sufridas por $T$. gondii en diferentes órganos en pollos. subinoculados con cerebros que provenían de pollos infectados con $10^{3}$ y $10^{5}$ ooquistes de $T$. gondii.

\section{DISCUSIÓN}

Aves y roedores son importantes hospederos intermediarios de $T$. gondii porque sirven como fuente de infección para gatos que excretan ooquistes en sus heces después de ingerir los quistes que están en tejidos de animales infectados. Aves como las gallinas adquieren fácilmente el parásito $T$. gondii debido a sus hábitos de alimentación, ya que pican la comida del suelo contaminado con ooquistes. Este comportamiento hace que se produzcan quistes en los tejidos de estos hospederos intermediarios, los cuales van a perpetuar la infección del parásito constituyendo un recurso de infección para los animales y el hombre ${ }^{10}$.

Estudios serológicos de $T$. gondii en gallinas que viven libres en el ambiente es un buen indicador de la prevalencia de este parásito. En Costa Rica un estudio de 50 gallinas reveló un $54 \%$ de persistencia del parásito ${ }^{5}$. En Rusia, se ha informado un $14 \%$ de gallinas domésticas infectadas, evidenciando que la seropositividad de las gallinas aumenta con la edad ${ }^{11}$. En Australia, es frecuente encontrar casos de aves salvajes con infecciones especialmente en la época de verano, a las cuales les produce la muerte por congestión pulmonar ${ }^{12}$.

Analizando los datos de la Figura 1 se puede observar una relación directa entre la cantidad del inóculo y la sobrevivencia de las aves ya que un mayor inóculo produjo mayor número de muertes. Los hematomas sólo estaban presentes en el intestino delgado de los animales infectados, 
no así en los controles, por lo que éstos se asociaron directamente con el inóculo de ooquistes de T. gondii. En otro estudio el estudio, utilizando aves de 10 a 15 semanas de edad infectadas con $T$. gondii por vía intracerebral, se demostró que a mayor inóculo menor supervivencia de las gallinas y que a menor edad, la probabilidad de morir de las aves era mayor. Además se determinó una diseminación hematógena en los primeros días de la infección y mediante un seguimiento de la parasitemia, se observa que ésta dura de 1 a 2 semanas después de administrado el inóculo; una mayor persistencia del Toxoplasma en sangre de los pollos se observó con los inóculos mayores, en los cuales además los animales presentaron mayor severidad en sus síntomas. Mediante infecciones experimentales en gallinas se ha encontrado que únicamente las gallinas jóvenes son las susceptibles a sufrir enfermedad ya que luego de inoculadas, las aves presentaron palidez y flacidez de cresta, pérdida de peso y diarrea, encontrándose el parásito en ovarios y en huevos de algunas gallinas ${ }^{13}$.

Los pollos, en este estudio, presentaron en el intestino delgado signos claros de daño tisular como áreas de hemorragias y hematomas, notándose que la intensidad de las lesiones fue proporcional al inóculo. Se puede hacer una correlación entre las características físicas de los pollos y la frecuencia de los hematomas, ya que en pollos con un inóculo menor presentaban aspecto más saludable, pocos hematomas, algunos en proceso de cicatrización.

Además en ese caso el pulmón de los animales no estaba tan afectado. Esto significa que con inóculos menores las aves desarrollan una respuesta inmune eficiente logrando controlar el parásito. Aún así éstas aves continúan siendo una fuente indirecta de infección para otros animales, ya que la carne de gallina puede ser dada a los gatos los cuales eliminan los ooquistes y de esta manera extenderse la infección por Toxoplasma al hombre.

Otros datos indican que las gallinas son relativamente tolerantes a $T$. gondii, requiriéndose un gran inóculo para afectar gallinas maduras y que pollos de corta edad son los más susceptibles ${ }^{14}$.

Además en aves viejas el parásito se disemina menos a órganos como cerebro, hígado y pulmón lo cual es mayor en animales jóvenes ${ }^{15}$. En este sentido algunos estudios indican que en gallinas infectadas en forma natural el $T$. gondii está distribuido irregularmente en tejidos como el cerebro, corazón y ovarios los cuales son más afectados que otros tejidos ${ }^{16}$.

En este trabajo se observó en los pollitos un pulmón hemorrágico, con congestión difusa acompañada de edema, inflamación con infiltrado granulocítico, zonas de necrosis con destrucción del parénquima y fibrosis, observándose taquizoitos tanto intra como extracelulares. En las aves que murieron debido al inóculo inicial, el hígado presentaba zonas multifocales fibrinopurulentas, lo cual contrasta con lo observado en gallinas viejas en donde la lesión hepática consiste de infiltrados periportales de fibrina condensada. También es notorio el hecho, como era de esperar, de que a mayores inóculos exista mayor daño en los órganos estudiados y mayor probabilidad de encontrar taquizoitos de $T$. gondii. Los signos patológicos encontrados en hígado y pulmón de los pollos estudiados en este trabajo son concordantes con lo observado por otros investigadores ${ }^{17}$.

En cuanto al estudio serológico realizado en los pollos, se comprobó la relación directa entre la positividad encontrada en las aves y el inóculo, observándose que los anticuerpos contra $T$. gondii fueron detectables más rápidamente y por más tiempo en animales con los inóculos más altos. Además esos anticuerpos fueron detectados luego de los 10 días, con un pico máximo de 10 a 15 días que luego declinó rápidamente hasta desaparecer por la prueba de la IFI utilizada en este estudio.

Estos hallazgos son concordantes con otro estudio en donde se estableció que los anticuerpos en sueros de aves son difíciles de detectar y además declinan rápidamente a bajos niveles ${ }^{13}$.

También se ha determinado que los títulos de anticuerpos desaparecen en las aves después de meses de infectadas, mientras que en los mamíferos permanecen por más tiempo, demostrando que las diferencias antigénicas no explican el comportamiento de la respuesta inmune entre ambas especies ${ }^{18}$.

La subinoculación de los cerebros de pollitos en ratones estudiados serológicamente, es un método que ayuda en este estudio a determinar la positividad de las aves, tal y como ha sido indicado previamente ${ }^{18}$.

Este trabajo da una idea del curso de la infección del $T$. gondii en pollitos de 5 días, 
analizando la importancia del inóculo en el desarrollo de la infección, el proceso de invasión a tejidos y el desarrollo de anticuerpos. Todo esto es de gran ayuda en el conocimiento de la importancia epidemiológica de las infecciones por este parásito en las aves de corral. Otro aspecto importante es el hecho de que la combinación de la serología y la subinoculación en ratones ofrece un mejor diagnóstico de $T$. gondii en pollitos.

\section{RESUMEN}

Pollitos (Gallus domesticus) de 5 días de nacidos fueron infectados oralmente con $10^{1}$, $10^{3}$ ó $10^{5}$ ooquistes de Toxoplasma gondii. Comparando con otro grupo de 5 pollitos sin inocular, se siguió el proceso de la infección observando la sintomatología, así como la supervivencia de los animales. Los órganos de aquellos que murieron fueron estudiados en su apariencia histopatológica. También se realizaron análisis serológicos para establecer la presencia de anticuerpos contra el parásito a través de la infección. Diarrea severa, anorexia y pérdida de peso en los animales precedieron la muerte que se inició a los cinco días, siendo la supervivencia inversamente proporcional al inóculo del parásito.

Los órganos más afectados fueron intestino, hígado y pulmón y la serología fue positiva después de 10 días de infección, aumentando a los 20 días para declinar posteriormente. La importancia epidemiológica de estas aves en la toxoplasmosis es discutida a la luz del proceso de infección observado.

\section{REFERENCIAS}

1.- FRENKEL J, RUIZ A. Toxoplasmosis humana. Acta Méd Costarr 1973; 16: 5-73.

2.- CHINCHILLA M. Epidemiología de la toxoplasmosis en Costa Rica y la importancia de los roedores domésticos. Rev Biol Tropl 1978; 26: 113-24.

3.- RODRÍGUEZ M R, REYES L, CHINCHILLA M. Análisis serológico por Toxoplasma gondii en ganado bovino de Costa Rica. Ciencias Vet 1990; 12: 17-9.
4.- TORRES A L, CHINCHILLA M, REYES L. Anticuerpos contra Toxoplasma gondii en cerdos de Costa Rica: importancia epidemiológica. Rev Latinoam Microb 1991; 33: 129-33.

5.- RUIZ A, FRENKEL J K. Intermediate hosts of Toxoplasma in Costa Rica. Am J Trop Med and Hyg 1980; 29: 1161-6.

6.- MAIRENA H, CHINCHILLA M, CHACÓN G, et al. Toxoplasma gondii en suelos del área urbana de San José Costa Rica. Rev Costarr Cienc Méd 1986; 7: 251-4.

7.- HOLST I, CHINCHILLA M. Development and distribution of cyst of an avirulent strain of Toxoplasma and the humoral immmune response in mice. Rev Biol Trop 1990; 38: 189-94.

8.- ARIAS M L, REYES L, CHINCHILLA M, LINDER E. Seroepidemiology of Toxoplasma gondii (Apicomplexa) in meat producing animals in Costa Rica. Rev Biol Trop 1994; 42: 15-20.

9.- DUBEY J P, FRENKEL J P. Experimental infection in mice with strains producing oocysts. J Parasitol 1973; 59: 505-12.

10.- AGANDA A O, BELINO E D. Toxoplasmosis in local breed of chicken in Zaria, Nigeria Intl $\mathrm{J}$ Zoonosis 1984; 11: 170-2.

11.- BEYER T V, SHEVKUNOVA E A. A review of Toxoplasmosis of animals in the U.S.S.R. Vet Parasitol 1986; 19: 225-43.

12.- HARTLEY W J, DUBEY J P. Fatal toxoplasmosis in some native Australian birds. J Vet Diag Inv 1991; 3: 167-9.

13.- JONES F E, MELTON M L, LUNDE M N, et al. Experimental Toxoplasmosis in chickens. J Parasitol 1959; 45: 31-7.

14.- JACOBS L, MELTON M L. Toxoplasmosis in Chickens. J Parasitol 1966; 52: 1158-62.

15.- HUBARD G, WITT W, HAELY M, SCHMIDT R. An Outbreak of Toxoplasmosis in Zoo Birds. Vet Pathol 1986; 23: 639-41.

16.- DUBEY J P, RUFF M D, CAMARGO M E, et al. Serologic and parasitologic responses of domestic chickens after oral inoculation with Toxoplasma gondii oocysts. Am Vet Res 1993; 54: 1668-72.

17.- PARENTI E, CERRUTISOLA S, TURILLI C, CORAZZOLA S. Spontaneous Toxoplasmosis in Canaries (Serinus canaria) and other small Passerine Cage Birds. Avian Pathol 1986; 15: 183- 97.

18.- FRENKEL J K. False Negative Serologic Test for Toxoplasma gondii in Birds. Parasitology 1981; 67: 952-3.

Agradecimientos: Este estudio fue financiado en parte por la Universidad de Costa Rica por medio del Proyecto 803A2-045 d la Vicerrectoría de investigación. 